\title{
A patient with Korsakoff syndrome of psychiatric and alcoholic etiology presenting as DSM-5 mild neurocognitive disorder
}

This article was published in the following Dove Press journal:

Neuropsychiatric Disease and Treatment

\author{
Georgios Nikolakaros $\mathbb{D}^{1,2}$ \\ Timo Kurki iD ${ }^{3,4}$ \\ Arttu Myllymäki ${ }^{\prime}$ \\ Tuula Ilonen ${ }^{5}$ \\ 'Satakunta Hospital District, Psychiatric \\ Care Division, General Psychiatry \\ Outpatient Clinic, Pori, Finland; ${ }^{2} \mathrm{HUS}$ \\ Medical Imaging Center, Department of \\ Clinical Neurophysiology, Helsinki \\ University Hospital, Helsinki, Finland; \\ ${ }^{3}$ Terveystalo Pulssi Medical Center, \\ Turku, Finland; ${ }^{4}$ Department of \\ Radiology, University of Turku, Turku, \\ Finland; ${ }^{5}$ Department of Psychiatry, \\ University of Turku, Turku, Finland
}

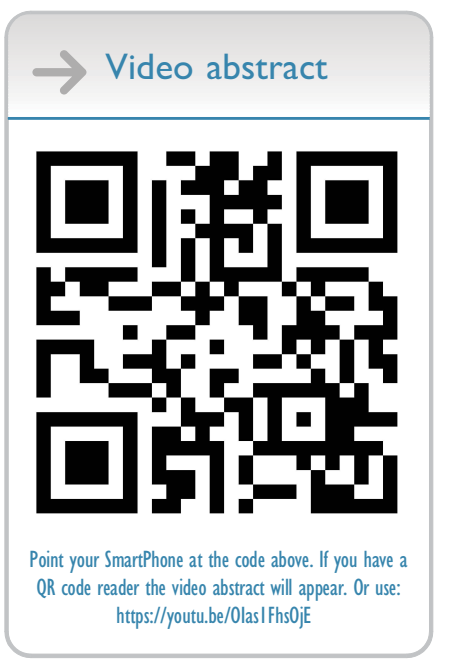

Correspondence: Georgios Nikolakaros Department of Clinical Neurophysiology, HUS Medical Imaging Center, Helsinki University Central Hospital,

Stenbäckinkatu 9, PL 100, HUS 00029,

Finland

Phone +358947182010

Fax +358947175500

Email georgios.nikolakaros@utu.fi
Background: Wernicke's encephalopathy (WE) and Korsakoff syndrome (KS) are underdiagnosed. The DSM-5 has raised the diagnostic threshold by including KS in the major neurocognitive disorders, which requires that the patient needs help in everyday activities.

Methods: We report clinical, neuropsychological, and radiological findings from a patient who developed Wernicke-Korsakoff syndrome as a result of alcohol use and weight loss due to major depression. We assess the diagnosis in the context of the scientific literature on KS and according to the DSM-IV and the DSM-5.

Results: The patient developed ataxia during a period of weight loss, thus fulfilling current diagnostic criteria of WE. WE was not diagnosed, but the patient partially improved after parenteral thiamine treatment. However, memory problems became evident, and KS was considered. In neuropsychological examination, the Logical Memory test and the Word List test were abnormal, but the Verbal Pair Associates test was normal (Wechsler Memory ScaleIII). There were intrusions in the memory testing. The Wisconsin Card Sorting Test was broadly impaired, but the other test of executive functions (difference between Trail Making B and Trail Making A tests) was normal. There was atrophy of the mammillary bodies, the thalamus, the cerebellum, and in the basal ganglia but not in the frontal lobes. Diffusion tensor imaging showed damage in several tracts, including the uncinate fasciculi, the cinguli, the fornix, and the corona radiata. The patient remained independent in everyday activities. The patient can be diagnosed with KS according to the DSM-IV. According to the DSM-5, the patient has major neurocognitive disorders.

Conclusions: Extensive memory testing is essential in the assessment of KS. Patients with a history of WE and typical clinical, neuropsychological, and radiological KS findings may be independent in everyday activities. Strict use of the DSM-5 may worsen the problem of Wernicke-Korsakoff syndrome underdiagnosis by excluding clear KS cases that do not have very severe functional impairment.

Keywords: alcoholism, depressive disorder, diffusion tensor imaging, Korsakoff syndrome, neurocognitive disorders, Wernicke encephalopathy

\section{Introduction}

Thiamine deficiency can cause Wernicke's encephalopathy (WE) and chronic cognitive impairment, Korsakoff syndrome (KS). ${ }^{1-6}$ Alcohol abuse may result in thiamine deficiency, but conditions unrelated to alcohol may cause malnutrition and WE. ${ }^{7,8}$ Major depression with associated malnutrition may cause WE in nonalcoholic patients $^{9-19}$ or in the presence of alcohol abuse. ${ }^{20,21} \mathrm{KS}$ has usually been associated with alcoholic WE, and only recently it has been fully appreciated 
that also non-alcoholic WE can cause KS. ${ }^{4,6,8,22}$ To diagnose KS, the DSM-IV ${ }^{23}$ and DSM- $5^{24}$ require functional impairment. Recently, the need for a comprehensive definition of KS has been noted. ${ }^{5}$

The core neuropsychological feature of KS is memory impairment. ${ }^{2,3,5,25}$ Executive functions are impaired in alcoholic $\mathrm{KS}^{26-32}$ but they may be normal in non-alcoholic $\mathrm{KS}^{4,6,33}$ It has been recently reported that in alcoholic KS the executive functions of shifting and updating are affected, whereas inhibition may be spared. ${ }^{32}$

Conventional brain MRI of patients with neuropsychologically documented non-alcoholic KS has been normal in most cases, but frontal lobe and vermis atrophy have been reported. ${ }^{4}$ Mammillary body (MB),${ }^{34-38}$ central,,${ }^{38-41}$ vermis, ${ }^{40,41}$ and thalamic atrophy ${ }^{38,42}$ have been shown in patients with cognitive symptoms following non-alcoholic WE. Alcoholic KS is associated with brain atrophy in cortical areas (particularly the frontal lobes), the MBs, the amygdala, the thalamus, the hippocampus, the corpus callosum, and the cerebellum. ${ }^{43,44}$

Diffusion Tensor Imaging (DTI) in KS has shown abnormalities in frontotemporal tracts (uncinate, cingulum), the fornix, the corpus callosum, the inferior longitudinal fasciculus, and the corona radiata. ${ }^{4,6,45,46}$

We describe Wernicke-Korsakoff syndrome (WKS) in a patient with major depression and alcohol use disorder. We describe neuropsychological, MRI, and DTI findings. We discuss functional impairment and the diagnostic use of the DSM-5.

\section{Material and methods Clinical description}

This male patient has had panic disorder and generalized anxiety disorder since the age of 31 , and major depression since the age of 51. The patient had been using large amounts of alcohol since his teen years. He had been on long-term disability leave from his job as shop manager. There was no history of traumatic brain injury or substance abuse other than alcohol.

At the age of 54, the patient's depression worsened for several months. He had poor appetite, and on several occasions, he did not eat anything for two to three consecutive days. His weight dropped by $11 \mathrm{~kg}$. During this period of malnutrition, heavy alcohol use continued. The patient was examined at the neurology outpatient clinic because of pain and weakness in the lower limbs. There was ataxia (wide-based walking, abnormal heel-shin test) and tremor, muscle weakness, and muscle wasting of the lower limbs. The patient walked with the help of a rollator. Electromyoneurography and muscle biopsy of the lower limbs were normal. Brain MRI showed some small diffuse vascular lesions. Cerebrospinal fluid examination was normal except for a slightly elevated protein concentration. Concentrations of gamma-glutamyl transpeptidase and carbohydrate-deficient transferrin were elevated $(76 \mathrm{U} / \mathrm{L}$ and $48 \%$, respectively), magnesium was low-normal ( 0.73 $\mathrm{mmol} / \mathrm{L}$, normal range $0.7-1.1$ ), whereas the rest of the blood tests (full blood count, sodium, potassium, calcium, thyroid tests, creatine kinase, alkaline phosphatase, 25hydroxy vitamin D, ferritin, B12-vitamin, folate) were normal. The diagnosis was leg weakness, and the patient was advised to stop using alcohol.

Five months later the patient's condition worsened, and he was treated daily with thiamine intramuscularly for several days as part of alcohol detoxification treatment. At the same time, he considerably reduced his alcohol use. During the next months, the lower limb symptoms partially resolved, and the patient was able to walk independently. However, one year after thiamine treatment, there was still muscle weakness. The patient was able to walk a maximum of four kilometers and could not bicycle uphill or run. He complained of severe memory problems. He had difficulties remembering past events, to which photographs helped. $\mathrm{He}$ could not resume watching a recorded TV-program after a 30-min break. There was a mild confabulation tendency presenting as wrong recollection of conversations with friends and relatives. The patient was living alone in his own home and was independent in basic everyday activities. The patient was evaluated for possible KS.

\section{Neuropsychological assessment}

The Vocabulary, Digit Symbol, Information, and LetterNumber Sequencing subtests of the Wechsler Adult Intelligence Scale-III (WAIS-III) were used to assess general cognitive level, psychomotor speed, general knowledge, and verbal working memory, respectively. General attention and divided attention were tested with the Trail Making A and B tests, respectively. We used the Wechsler Memory Scale-III (WMS-III) to test memory. In testing auditory/verbal memory, we used the Logical Memory subtest and both word list subtests: the Word List test that contains 12 unrelated words and the Verbal Pair Associates (VPA) test that contains 8 word pairs. The words of each pair are semantically unrelated, but it is possible for the test subject to form associations that 
facilitate remembering. ${ }^{47}$ Testing of executive functions comprised set shifting (Wisconsin Card Scoring Test/ WCST: number of categories achieved and number of perseverative errors) and task switching (the score difference between Trail Making Tests B and A). Results at least 1.5 standard deviations (SDs) below the mean of normative values were considered abnormal for all tests except the WCST, for which we used the -1 SD threshold suggested in the test manual. ${ }^{48}$ Intrusions were defined as false words and statements in the WMS-III.

\section{DTI and conventional brain MRI}

MRI and DTI were performed as previously described. ${ }^{4,6,49}$ Volumetric analysis was performed with the FDA-approved cNeuro cMRI software (Combinostics, Finland). ${ }^{50}$ Brain area volumes were measured in milliliters, and age- and sex-adjusted volume z-scores were calculated based on the comparison with controls. Z-scores $\leq 1$ were considered indicative of atrophy. ${ }^{43}$ The neocortical areas (frontal, temporal, parietal, and occipital lobes separately) were evaluated with the Pasquier's global cortical atrophy (GCA) scale. ${ }^{51}$ In addition, the MBs were manually outlined in $1.0 \mathrm{~mm}$ thick coronal reconstructions of $3 \mathrm{D} \mathrm{T} 1$ images, and their volume in milliliters was compared to 20 ageand sex-matched controls.
In DTI analysis, fractional anisotropy (FA) values at least 2 SDs smaller than those of 11 normal controls matched for age and sex were considered abnormal. Prior to the neuropsychological examination and the brain imaging, the patient had greatly reduced his alcohol use for three months, with normal values of carbohydratedeficient transferrin, erythrocyte mean corpuscular volume, alanine aminotransferase, and gamma-glutamyl transpeptidase. Medication at that time comprised quetiapine $75 \mathrm{mg}$ in the evening and clonazepam $0.5 \mathrm{mg}$ twice per day for mood and anxiety symptoms.

\section{Consent to participate}

The study complied with the Declaration of Helsinki. The patient gave written informed consent for the use of his medical information in this publication. The study was approved by the Satakunta Central Hospital. The Finnish legislation does not require any further permissions.

\section{Results}

Abnormal memory results were found in tests of verbal working memory, immediate and delayed verbal recall, and in verbal and visual recognition (Table 1). The WMS-III Word List subtest was abnormal, but the VPA test was normal. There were two non-semantic intrusions in the

Table I Results of memory tests for a patient with Korsakoff syndrome

\begin{tabular}{|c|c|c|}
\hline Cognitive domain & Test & Z-score \\
\hline \multicolumn{3}{|l|}{ Working memory } \\
\hline Verbal & WAIS-III', Letter-Number Sequencing & -1.67 \\
\hline Visual & WMS-III', Spatial Span & -1 \\
\hline \multicolumn{3}{|l|}{ Episodic memory } \\
\hline \multicolumn{3}{|l|}{ Immediate recall } \\
\hline Verbal (logical) & WMS-III', Logical Memory I & -1.67 \\
\hline Verbal (word list) & WMS-III', Verbal Paired Associates & -0.67 \\
\hline Verbal (word list) & WMS-III', Word Lists & -2.67 \\
\hline Visual & WMS-III', Visual Reproduction I & -0.67 \\
\hline \multicolumn{3}{|l|}{ Delayed recall } \\
\hline Verbal (logical) & WMS-III', Logical memory II & -2 \\
\hline Verbal (word list) & WMS-III', Verbal Paired Associates & -1 \\
\hline Verbal (word list) & WMS-III', Word lists & -2.67 \\
\hline Visual & WMS-III', Visual Reproduction II & -0.67 \\
\hline \multicolumn{3}{|l|}{ Recognition } \\
\hline \multirow[t]{3}{*}{ Verbal } & WMS-III', Logical Memory II + Verbal & \\
\hline & Paired Associates II & -3 \\
\hline & WMS-III', Word Lists & -3 \\
\hline Visual & WMS-III', Visual Recognition & -2 \\
\hline
\end{tabular}

Notes: Values of -I.5 or less (Z-score) are in bold. The patient's results were compared to age-adjusted normative values. ${ }^{2}$ Wechsler Adult Intelligence Scale-III. ${ }^{b}$ Wechsler Memory Scale-III. 
VPA test, and in the Logical Memory test, there were five semantic and one non-semantic intrusion. In the other neuropsychological tests (Table 2), abnormal results were found in the Information subset of the WAIS-III and in the setshifting test of executive functions (WCST).

In brain volumetric analysis, atrophy changes were found in the hypothalamus, the MBs, the left hippocampus, the nucleus accumbens, the caudate, the pallidum, the thalamus, and the vermis (Table 3). In addition, there was general reduction of white-matter volume. CGA values were well within normal limits. Abnormal FA-values were found in several white matter tracts, including frontotemporal tracts (uncinate fasciculi, cingulum) (Table 4). Figure 1 shows atrophy changes. Figure 2 shows a DTI reconstruction of damaged white-matter tracts.

\section{Discussion}

We describe a patient with WKS caused by depressionrelated malnourishment and alcohol. At the time of WE, the patient had lost weight, and he was ataxic. Thus, the WE diagnostic threshold of two out of four diagnostic criteria (nutritional deficiency, ataxia, oculomotor abnormalities, altered mental state or mild memory impairment) proposed by Caine et $\mathrm{a}^{52}$ was reached.

\section{Neuropsychological findings}

The neuropsychological examination showed cognitive impairment, memory being preferentially affected. Logical memory and learning of unrelated words were most severely affected, whereas learning of words that can be semantically interconnected (VPA test) was normal. Patients with KS may have partially preserved anterograde semantic memory and be able to recruit associative mechanisms. ${ }^{53}$ Preferential impairment in the VPA test has been demonstrated in individuals with agenesis of the corpus callosum with normal interhemispheric connectivity being a prerequisite for a strong self-generated semantic network that supports encoding. ${ }^{47}$ Interestingly, the corpus callosum FA-values of our patient were normal.

We have recently shown that in patients with nonalcoholic KS the logical memory test may be abnormal, and the word list test may be normal and vice versa. ${ }^{6}$ Taken together with findings from the present patient, these results corroborate our previous suggestion on the need for a comprehensive neuropsychological evaluation of patients with suspected KS. ${ }^{6}$ Among word list tests, those containing unrelated words might have a better sensitivity. Had this patient been tested only with the VPA test or another word test that uses semantically related words, it could have been erroneously concluded that there is no memory impairment.

Similarly to previous studies, the patient made intrusions both in the logical memory test ${ }^{4,6}$ and the word list test. ${ }^{4,6,54}$ This further supports the usefulness of intrusions in examining patients with suspected KS.

In the WCST, both orbital prefrontal and dorsolateral prefrontal functions were affected. This is in accordance with previous findings in $\mathrm{KS}^{27,32}$

In alcoholic KS, executive dysfunction is common, ${ }^{26-32}$ but in non-alcoholic KS, executive functions appear to be largely preserved. ${ }^{4,6,33}$ There are several possible explanations for this discrepancy. Executive dysfunction in alcoholic KS could be due to a toxic effect of alcohol to the frontal lobes, ${ }^{26}$ and coexistence with thiamine-deficiency

Table 2 Results of neuropsychological tests other than memory for a patient with Korsakoff syndrome

\begin{tabular}{|l|l|l|}
\hline Cognitive domain & Test & Z-score \\
\hline General cognitive level & Vocabulary subset (WAIS-III ${ }^{\mathrm{a}}$ & -0.67 \\
\hline General knowledge & Information subset (WAIS-III ${ }^{\mathrm{a}}$ & $\mathbf{- 2 . 3 3}$ \\
\hline General attention & Trail Making Test A & 0.82 \\
\hline Divided attention & Trail Making Test B & 0 \\
\hline Psychomotor speed & Digit Symbol subset (WAIS-III) & - I \\
\hline $\begin{array}{l}\text { Executive functions I (set shifting) } \\
\text { Orbital prefrontal functions } \\
\text { Dorsolateral prefrontal functions }\end{array}$ & WCST , number of perseverative errors & $\mathbf{- 3}$ \\
\hline Executive functions II (task switching) & WCST , number of categories completed & $\mathbf{- I . 4 I}$ \\
\hline
\end{tabular}

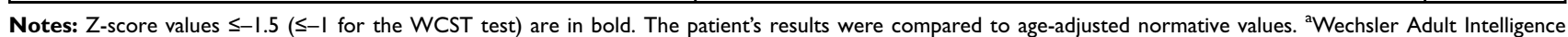
Scale-III. 'Wisconsin Card Scoring Test. 
Table 3 Brain MRI volumetric analyses in a patient with Korsakoff syndrome.

\begin{tabular}{|c|c|c|c|}
\hline Brain area & $\begin{array}{c}\text { Volume } \\
\text { (ml) }\end{array}$ & $\begin{array}{l}\% \\
\text { value }\end{array}$ & Z-score \\
\hline Brain stem & 18.2 & 29 & -0.55 \\
\hline Hemispheric gray matter total & 598 & 56 & 0.15 \\
\hline Hemispheric gray matter right & 300 & 57 & 0.18 \\
\hline Hemispheric gray matter left & 298 & 54 & 0.10 \\
\hline Hemispheric white matter & 404 & 7 & -1.48 \\
\hline Cerebrospinal fluid & 49.2 & 94 & 1.55 \\
\hline Entorhinal area, right & 2.71 & 85 & 1.04 \\
\hline Entorhinal area, left & 2.25 & 51 & 0.03 \\
\hline Hippocampus, right & 3.67 & 27 & -0.61 \\
\hline Hippocampus, left & 3.22 & 10 & -1.28 \\
\hline Amygdala, right & 1.17 & 47 & -0.08 \\
\hline Amygdala, left & 1.13 & 32 & -0.47 \\
\hline Nucleus accumbens, right & 0.34 & 4 & -1.75 \\
\hline Nucleus accumbens, left & 0.33 & I & -2.33 \\
\hline Caudate nucleus, right & 2.79 & 7 & -1.48 \\
\hline Caudate nucleus, left & 2.65 & 3 & -1.88 \\
\hline Pallidum, right & 1.29 & 9 & -1.34 \\
\hline Pallidum, left & 1.29 & 12 & -1.17 \\
\hline Putamen, right & 4.74 & 66 & 0.41 \\
\hline Putamen, left & 4.63 & 48 & -0.05 \\
\hline Thalamus, right & 7.13 & 7 & -1.48 \\
\hline Thalamus, left & 7.32 & 8 & $-1.4 \mid$ \\
\hline Hypothalamus, right & 4.17 & 7 & -1.48 \\
\hline Hypothalamus, left & 4.21 & 4 & -1.75 \\
\hline Cerebellar vermal lobules I - V & 3.41 & 10 & -1.28 \\
\hline Cerebellar vermal lobules VI - VII & 1.61 & 13 & -1.13 \\
\hline Cerebellar vermal lobules VIII - X & 2.19 & 9 & -1.34 \\
\hline Cerebellum exterior, right & 49 & 23 & -0.74 \\
\hline Cerebellum exterior, left & 49.8 & 36 & -0.36 \\
\hline Cerebellum white matter, right & 11.7 & 15 & -1.04 \\
\hline Cerebellum white matter, left & 11.9 & 23 & -0.74 \\
\hline Mammillary bodies (right + left) & 112 & 9 & -1.32 \\
\hline
\end{tabular}

Notes: The volume of the mammillary bodies was compared to 20 healthy controls. For the rest of the brain areas, the cNeuro cMRI software was used. Values $<-I$ (for gray or white matter brain areas) and >I (for CSF areas) are in bold.

induced memory impairment may be incidental. Another possible explanation is a selection bias, due to recruitment of KS study subjects from nursing facilities. Residents of nursing facilities are very probable to have executive dysfunction (since they cannot live independent lives). Van Oort and Kessels have shown that KS patients residing in nursing facilities have executive dysfunction, ${ }^{28}$ and Bowden has noted that studies of alcoholic KS are biased toward including more severe cases. ${ }^{55}$ In contrast, our previously reported patients with non-alcoholic KS and normal or minimally impaired executive functions were identified by screening psychiatric outpatients for previously undiagnosed WE. ${ }^{4,6}$ Alternatively, repeated episodes of WE may
Table 4 Fractional anisotropy (FA) values from diffusion tensor imaging in a patient with Korsakoff syndrome

\begin{tabular}{|c|c|c|}
\hline White matter tract & $\begin{array}{l}\text { Tractography } \\
\text { threshold }\end{array}$ & Z-score \\
\hline Corpus callosum genu & $0.50 / 27$ & -1.2 \\
\hline Corpus callosum body & $0.50 / 27$ & -1.1 \\
\hline Corpus callosum splenium & $0.50 / 27$ & -0.8 \\
\hline Superior cingulum, right & $0.15 / 27$ & -2.5 \\
\hline Superior cingulum, left & $0.15 / 27$ & -2.0 \\
\hline Inferior cingulum, right & $0.15 / 27$ & -2.2 \\
\hline Inferior cingulum, left & $0.15 / 27$ & -2.3 \\
\hline Subgenual cingulum, right & $0.15 / 27$ & -2.8 \\
\hline Subgenual cingulum, left & $0.15 / 27$ & -2.5 \\
\hline Uncinate fasciculus, right & $0.15 / 27$ & -2.2 \\
\hline Uncinate fasciculus, left & $0.15 / 27$ & -2.1 \\
\hline $\begin{array}{l}\text { Superior longitudinal fasciculus, } \\
\text { right }\end{array}$ & $0.15 / 27$ & -3.0 \\
\hline Superior longitudinal fasciculus, left & $0.15 / 27$ & -1.2 \\
\hline Inferior longitudinal fasciculus, right & $0.15 / 27$ & -3.1 \\
\hline Inferior longitudinal fasciculus, left & $0.15 / 27$ & -2.1 \\
\hline Arcuate fasciculus, left & $0.15 / 27$ & -1.9 \\
\hline $\begin{array}{l}\text { Inferior fronto-occipital fasciculus, } \\
\text { right }\end{array}$ & $0.15 / 27$ & -1.3 \\
\hline $\begin{array}{l}\text { Inferior fronto-occipital fasciculus, } \\
\text { left }\end{array}$ & $0.15 / 27$ & -1.4 \\
\hline Anterior corona radiata, right & $0.15 / 27$ & -2.0 \\
\hline Anterior corona radiata, left & $0.15 / 27$ & -1.5 \\
\hline $\begin{array}{l}\text { Frontostriatal projection fibers, } \\
\text { right }\end{array}$ & $0.15 / 27$ & -1.6 \\
\hline Frontostriatal projection fibers, left & $0.15 / 27$ & -1.9 \\
\hline Mesencephalic projections, right & $0.30 / 27$ & -1.5 \\
\hline Mesencephalic projections, left & $0.30 / 27$ & -0.3 \\
\hline Fornix, right & $0.15 / 40$ & -1.8 \\
\hline Fornix, left & $0.15 / 40$ & -2.0 \\
\hline Descending fornix, right & $0.15 / 40$ & -2.2 \\
\hline Descending fornix, left & $0.15 / 40$ & -1.7 \\
\hline
\end{tabular}

Notes: Z-scores represent the difference from the mean of controls with one standard deviation as the unit. Values $\leq-2$ are in bold.

cause executive dysfunction, and patients with long-term alcoholism are more probable to have repeated WE episodes compared to non-alcoholic WE patients. However, we have recently reported on a patient with two separate WE episodes caused by hyperemesis gravidarum who developed non-alcoholic KS without executive dysfunction. ${ }^{4}$

One of the tests we used to assess executive functions was the WCST. Similarly to previous studies. ${ }^{25,27,56,57}$ both the number of categories completed and the number of perseveration errors were abnormal. This dual abnormality may differentiate alcoholic KS patients from patients with other causes of organic amnesia. ${ }^{56,57}$ Although frequently associated with frontal lobe atrophy, abnormal 


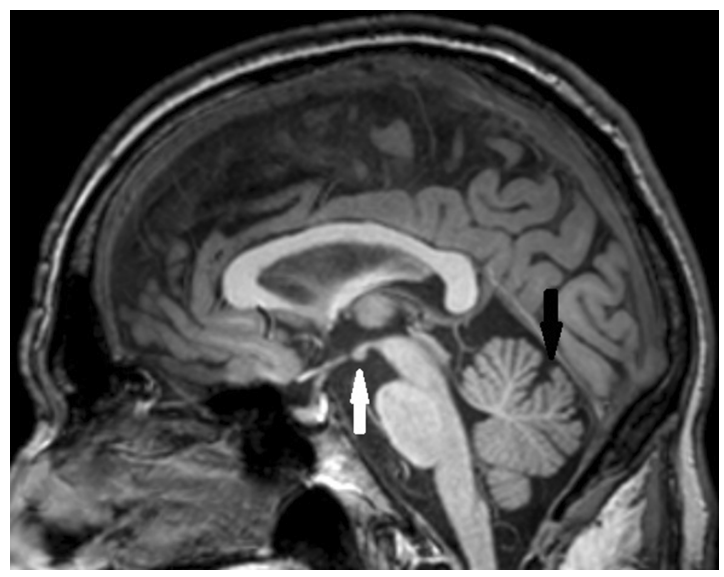

Figure I MRI sagittal image showing mild mammillary body atrophy (white arrow) and mild vermis atrophy (black arrow).

results in the WCST may also be due to lesions in the thalamus, the basal ganglia, the cerebellum, and frontostriatal white matter tracts. ${ }^{58}$ The thalamus, the basal ganglia, and the cerebellum, but not the frontal lobes, showed signs of atrophy in our patient. The frontostriatal tracts had reduced FA-values but below the $-2 \mathrm{SD}$ threshold we used. Similarly to previous studies, ${ }^{4,6,30}$ the task switching test (Trail B - Trail A score) was normal.

\section{Neuroimaging findings}

MRI showed more than $1 \mathrm{SD}$ volume reduction in the thalamus, the MBs, and the vermis, as severe as in typical alcoholic KS. ${ }^{43}$ Atrophy was also found in the basal ganglia, a brain area that can be affected in WKS. ${ }^{59}$ However, contrary to findings in patients with alcohol use disorder, ${ }^{60}$ there was no cortical atrophy. This underscores the importance of thiamine deficiency in the development of $\mathrm{KS}$ in the present patient as opposed to a direct effect of alcohol.

DTI showed extensive damage in white matter tracts. Similarly to previous KS studies, damage was shown in the Papez circuit (fornix), ${ }^{46}$ frontotemporal tracts (uncinate fasciculus, cingulum), ${ }^{4,6}$ the inferior longitudinal fasciculus, ${ }^{4}$ and the anterior corona radiata. ${ }^{4,45}$ There was also damage in the superior longitudinal fasciculus, which has been recently shown to be affected in alcoholic men. ${ }^{61}$ Together with results from previous studies, ${ }^{4,6,45,46}$ our results support the importance of DTI in exploring brain damage in WKS. Damage in the uncinate fasciculus and the temporal cingulum supports our previous suggestion on the importance of frontotemporal tract involvement in WKS. $^{6}$

\section{KS diagnosis}

The clinical history and the results of the neuropsychological and radiological examinations support the diagnosis of KS. However, when considering functional impairment, the patient can be diagnosed with $\mathrm{KS}$ according to the DSM-IV but not according to the DSM-5.

The DSM-IV mentions KS as alcohol-induced persisting amnestic disorder due to thiamine deficiency. The DSM-5 changed the classification of neurocognitive disorders (NCDs) by introducing a baseline distinction between major and mild NCDs. ${ }^{24} \mathrm{~A}$ defining characteristic of major NCD is inability to function independently in everyday life. The DSM-5 mentions thiamine deficiency and alcohol as independent causes of major and mild
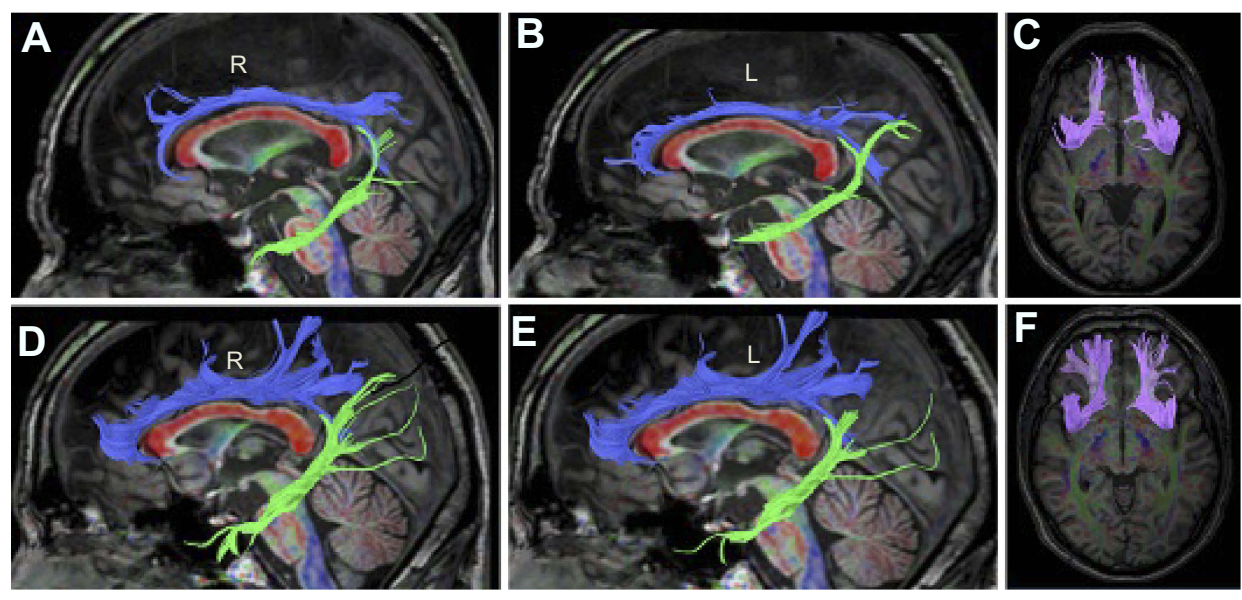

Figure 2 Tractograms of the patient (A, B, C) and a control subject (D, E, F). The control subject's tractograms are of average size. The superior cingulum is in blue, the inferior cingulum is in green, and the corpus callosum is in red (A, B, D, E). The fasciculus uncinatus is in magenta (C, F). The patients' tractograms (except for the corpus callosum) are markedly smaller than the tractograms of the control. R, Right side, L, Left side. 
NCD. KS is mentioned as alcohol-induced amnestic confabulatory major NCD with prominent amnesia and a tendency to confabulate.

Therefore, the DSM-5 has raised the threshold to diagnose KS. A person with memory impairment that cannot work but is independent in everyday life could have been diagnosed with KS in DSM-IV but cannot be diagnosed with KS with DSM-5. Interestingly, the other NCDs may manifest both as major and mild, and KS appears to be the only exception.

The DSM-5 inappropriately restricts the use of the term $\mathrm{KS}$ to cases were the memory impairment was caused by alcohol and the patient confabulates ("alcohol-induced amnestic confabulatory NCD"). However, it has been shown that KS may occur as a result of non-alcoholic WE. ${ }^{4,6,8,22,33}$ Spontaneous confabulations are uncommon in chronic KS. ${ }^{2}$

As illustrated by the present patient, patients with partially preserved functioning after WE may fit diagnostically within the current clinical and research framework of KS. It is possible to use the DSM- 5 terms mild NCD due to a medical disorder (thiamine deficiency), mild NCD due to alcohol, or (as in the current patient) use both diagnoses.

According to the DSM-5, neuropsychological test results between -1 and -2 SDs below the normative mean are associated with mild NCD, whereas more deviant test results (at least -2 SDs below the normative mean) suggest major NCD. Our patient had test results compatible with major NCD on most abnormal memory test results.

Three considerations further support the use of the KS diagnosis for patients with DSM-5 mild NCD. First, the DSM-5 encourages a disorder conceptualization based on empirical validation of biological determinants. Researchers and clinicians are encouraged to use the Alzheimer's disease diagnosis instead of Mild Cognitive Impairment for patients with cerebrospinal fluid, positronemission tomography, and neuropsychological findings compatible with Alzheimer's disease, even with not severe functional impairment. Second, thiamine deficiency can vary in severity and duration, and so can vary the adequacy of thiamine treatment. Presumably, the ensuing brain damage and functional impairment will vary in severity. Mild memory impairment after WE has been mentioned in many previous reports.. ${ }^{34,62-77}$ We have previously reported on a patient with non-alcoholic KS and atypical neuropsychological presentation that also presented with mild NCD. ${ }^{6}$ Third, WKS is greatly underdiagnosed, particularly in non-alcoholic patients. ${ }^{2,4,6,7}$ Given the devastating effects of undiagnosed and untreated WKS, it is not wise to raise the diagnostic threshold in the absence of supporting empirical evidence.

Major depression may cause cognitive impairment, but comorbid affective disorder does not exacerbate the effects of alcohol use on cognition. ${ }^{75}$ Chronic alcoholism may cause cognitive problems, but abstinence is associated with substantial recovery. ${ }^{76}$ The present patient presented memory complaints only after the WE. The presence of intrusions in memory testing is suggestive of organic memory impairment. ${ }^{4,6}$ Deficiency of other micronutrients may have contributed to the cognitive problems. ${ }^{77}$

\section{Other clinical aspects}

The patient presented with severe muscle weakness that partially improved after thiamine treatment. Partially improved muscle weakness has been previously described in WKS. ${ }^{6,74,78}$

The underdiagnosis of KS has been attributed to patients being diagnosed with alcoholic dementia when the cognitive impairment has been in fact caused by thiamine deficiency. ${ }^{55}$ Psychiatric patients with non-alcoholic KS are another underdiagnosed group. ${ }^{4,6}$ Our results, together with results from our previous reports, ${ }^{4,6}$ may help identify KS patient who despite clear memory impairment live relatively independent lives.

The patient in the present report developed thiamine deficiency as a result of psychiatric disease (major depression) and alcohol use. Major depression is associated with weight loss, ${ }^{24}$ and comorbid alcohol use disorder is common. ${ }^{79}$ Thus, depressed patients may be at high risk for WKS. To our knowledge, there are 12 previous reports of major depression causing malnutrition and WE. ${ }^{9,10,12-18,20,21}$ Two of these patients had concomitant alcohol use disorder. ${ }^{20,21}$ In our patient, treatment with parenteral thiamine was delayed, which possibly resulted in long-term memory impairment and muscle weakness. This underlines the importance of early recognition and treatment of WE but also the usefulness of routine administration of parenteral thiamine in alcohol detoxification. ${ }^{80}$

The continuity theory claims that alcohol affects memory along a continuum with KS patients being gravely impaired. ${ }^{81}$ However, as the present report illustates, it is not possible to know whether a patient with clear but not debilitating memory impairment has mild KS or is an "uncomplicated alcoholic". 55 This supports the notion 
that previous results in support of the continuity theory may instead reflect a continuum of memory impairment caused by thiamine deficiency. ${ }^{5}$

We have previously reported on six psychiatric patients with $\mathrm{KS}$ and previously undiagnosed nonalcoholic WE, which were identified through systematic consideration of WKS in psychiatric patients with prominent memory complaints. ${ }^{4,6}$ The present patient extends the usefulness of this clinical approach to patients with previously undiagnosed WE of mixed etiology (alcoholic and psychiatric).

\section{Limitations}

Our study has several limitations. Data come from only one patient. Larger studies are needed to further explore imaging and neuropsychological features of relatively mild WKS. We assessed executive functions with only two tests. A more thorough examination could have provided a more complete picture of impairment and preserved skills. We did not examine the frontocerebellar tracts that may be affected in WKS. ${ }^{45,82}$

\section{Conclusions}

In summary, we present a patient that developed WKS as a result of depression and alcohol use. The patient's chronic memory impairment has compromised his working ability, but he does not need assistance in everyday life. The patient can be diagnosed with $\mathrm{KS}$ according to the DSM-IV but not according to the DSM-5. However, all the core neuropsychological and radiological findings of $\mathrm{KS}$ were present. Strict use of the DSM-5 in evaluating patients suspected of having KS may lead to underdiagnosis. Finally, the memory testing of patients with suspected KS should be comprehensive and include word list tests containing semantically unrelated items.

\section{Abbreviation list}

DTI, diffusion tensor imaging; FA, fractional anisotropy; KS, Korsakoff syndrome; MB, mammillary body; NCD, neurocognitive disorder; SD, standard deviation; VPA, verbal pair associates; WCST, Wisconsin Card Scoring Test; WE, Wernicke's encephalopathy; WKS, WernickeKorsakoff syndrome; WMS-III, Wechsler memory scaleIII.

\section{Disclosure}

The authors declare that the research was conducted in the absence of any commercial or financial relationships that could be construed as a potential conflict of interest.

\section{References}

1. Pietro SG, Serra A. Wernicke's encephalopathy: new clinical settings and recent advances in diagnosis and management. Lancet Neurol. 2007;6(5):442-455. doi:10.1016/S1474-4422(07)70104-7

2. Kopelman MD, Thomson AD, Guerrini I, Marshall EJ. The Korsakoff syndrome: clinical aspects, psychology and treatment. Alcohol Alcohol. 2009;44(2):148-154. doi:10.1093/alcalc/agn118

3. Isenberg-Grzeda E, Kutner HE, Nicolson SE. Wernicke-Korsakoffsyndrome: under-recognized and under-treated. Psychosomatics. 2012;53(6):507-516. doi:10.1016/j.psym.2012.04.008

4. Nikolakaros G, Ilonen T, Kurki T, Paju J, Papageorgiou SG, Vataja R. Non-alcoholic Korsakoff syndrome in psychiatric patients with a history of undiagnosed Wernicke's encephalopathy. J Neurol Sci. 2016;370:296-302. doi:10.1016/j.jns.2016.09.025

5. Arts N, Walvoort S, Kessels R. Korsakoff's syndrome: a critical review. Neuropsychiatr Dis Treat. 2017;13:2875-2890. doi:10.2147/ NDT.S130078

6. Nikolakaros G, Kurki T, Paju J, Papageorgiou SG, Vataja R, Ilonen T. Korsakoff syndrome in non-alcoholic psychiatric patients. Variable cognitive presentation and impaired frontotemporal connectivity. Front Psychiatry. 2018;9(MAY). doi:10.3389/fpsyt.2018.00204

7. Galvin R, Bråthen G, Ivashynka A, Hillbom M, Tanasescu R, Leone MA. EFNS guidelines for diagnosis, therapy and prevention of Wernicke encephalopathy. Eur J Neurol. 2010;17(12):1408-1418. doi:10.1111/j.1468-1331.2010.03153.x

8. Scalzo SJ, Bowden SC, Ambrose ML, Whelan G, Cook MJ. Wernicke-Korsakoff syndrome not related to alcohol use: a systematic review. J Neurol Neurosurg Psychiatry. 2015;86 (12):1362-1368. doi:10.1136/jnnp-2014-309598

9. Dias SP, Diogo MC, Capela C, Marques R, Gonçalves M. Wernicke's encephalopathy due to food refusal in a patient with severe depressive disorder. $J$ Neurol Sci. 2017;375:92-93. doi:10.1016/j. jns.2017.01.052

10. Merkin-Zaborsky H, Ifergane G, Frisher S, Valdman S, Herishanu Y, Wirguin I. Thiamine-responsive acute neurological disorders in nonalcoholic patients. Eur Neurol. 2001;45(1):34-37. doi:10.1159/000052086

11. Lee SM, Kang WS, Cho AR, Park JK. Wernicke's encephalopathy confirmed via brain MRI in cancer patient. Aust N Z J Psychiatry. 2012;46(1):70-71. doi:10.1177/0004867411427817

12. Nasrallah KM, Mitsias PD. Orthostatic tremor due to thiamine deficiency [7]. Mov Disord. 2007;22(3):440-441. doi:10.1002/mds.21193

13. Stone R, Archer JS, Kiernan M. Wernicke's encephalopathy mimicking variant Creutzfeldt-Jakob disease. J Clin Neurosci. 2008;15 (11):1308-1310. doi:10.1016/j.jocn.2007.05.022

14. Shin RK, Galetta SL, Imbesi SG. Wernicke encephalopathy. Arch Neurol. 2000;57(3):405. doi:10.1001/archneur.57.3.405

15. Sharma S, Sumich PM, Francis IC, Kiernan MC, Spira PJ. Wernicke's encephalopathy presenting with upbeating nystagmus. J Clin Neurosci. 2002;9(4):476-478. doi:10.1054/jocn.2002.1121

16. Olsen RQ, Regis JT. Delirious deficiency. Lancet. 2010;376 (9749):1362. doi:10.1016/S0140-6736(10)61010-0

17. Cocksedge KA, Flynn A. Wernicke-Korsakoff syndrome in a patient with self-neglect associated with severe depression. JRSM Open. 2014;5(2):2042533313518915. doi:10.1177/2042533313518915

18. Frijlink DW, Tilanus JJ, Roks G. Elevated cerebrospinal fluid tau in Wernicke encephalopathy. BMJ Case Rep. 2012;2012. doi:10.1136/ bcr-2012-006661 
19. Ishibashi S. Reversible acute axonal polyneuropathy associated with Wernicke-Korsakoff syndrome: impaired physiological nerve conduction due to thiamine deficiency? J Neurol Neurosurg Psychiatry. 2003;74(5):674-676. doi:10.1136/jnnp.74.5.674

20. Sabatini JS, Schutz-Pereira GL, Feltrin F, Teive HAG, Camargo CHF. Wernicke's encephalopathy with chorea: neuroimaging findings. Dement Neuropsychol. 2016;10(4):370-372. doi:10.1590/s19805764-2016dn1004020

21. Karayiannakis AJ, Souftas VD, Bolanaki H, Prassopoulos P, Simopoulos C. Wernicke encephalopathy after pancreaticoduodenectomy for pancreatic cancer. Pancreas. 2011;40(7):1157-1159. doi:10.1097/MPA.0b013e31822182f5

22. Lough ME. Wernicke's encephalopathy: expanding the diagnostic toolbox. Neuropsychol Rev. 2012;22(2):181-194. doi:10.1007/ s11065-012-9200-7

23. American Psychiatric Association. Diagnostic and Statistical Manual of Mental Disorders. 4th. Washington, DC: American Psychiatric Association; 2000. doi:10.1176/appi.books.9780890423349

24. American Psychiatric Association. Diagnostic and Statistical Manual of Mental Disorders. 5th ed. Washington, DC: American Psychiatric Association; 2013.

25. Fama R, Marsh L, Sullivan EV. Dissociation of remote and anterograde memory impairment and neural correlates in alcoholic Korsakoff syndrome. J Int Neuropsychol Soc. 2004;10(3):427-441. doi:10.1017/S135561770410310X

26. Brokate B, Eling P, Hildebrandt H, Fichtner H, Runge K, Timm C. Frontal lobe dysfunctions in Korsakoff's syndrome and chronic alcoholism: continuity or discontinuity? Neuropsychology. 2003;17 (3):420-428. doi:10.1037/0894-4105.17.3.420

27. Dirksen CL, Howard JA, Cronin-Golomb A, Oscar-Berman M. Patterns of prefrontal dysfunction in alcoholics with and without Korsakoff's syndrome, patients with Parkinson's disease, and patients with rupture and repair of the anterior communicating artery. Neuropsychiatr Dis Treat. 2006;2(3):327-339. doi:10.2147/nedt.2006.2.3.327

28. Van Oort R, Kessels RPC. Executive dysfunction in Korsakoff's syndrome: time to revise the DSM criteria for alcohol-induced persisting amnestic disorder? Int J Psychiatry Clin Pract. 2009;13 (1):78-81. doi:10.1080/13651500802308290

29. Oscar-Berman M. Function and dysfunction of prefrontal brain circuitry in alcoholic Korsakoff's syndrome. Neuropsychol Rev. 2012;22 (2):154-169. doi:10.1007/s11065-012-9198-x

30. Maharasingam M, Macniven JAB, Mason OJ. Executive functioning in chronic alcoholism and Korsakoff syndrome. J Clin Exp Neuropsychol. 2013;35(5):501-508. doi:10.1080/13803395.2013. 795527

31. Brion M, Pitel A-L, Beaunieux H, Maurage P. Revisiting the continuum hypothesis: toward an in-depth exploration of executive functions in korsakoff syndrome. Front Hum Neurosci. 2014;8:498. doi:10.3389/fnhum.2014.00498

32. Moerman-van den Brink WG, van Aken L, Verschuur EML, Walvoort SJW, Egger JIM, Kessels RPC. Executive Dysfunction in Patients With Korsakoff's Syndrome: A Theory-Driven Approach. Alcohol Alcohol. 2019;54(1):23-29. doi:10.1093/alcalc/agy078

33. Gasquoine PG. A case of bariatric surgery-related wernicke-korsakoff syndrome with persisting anterograde amnesia. Arch Clin Neuropsychol. 2017;32(5):610-617. doi:10.1093/arclin/acx037

34. Gascón-Bayarri J, Campdelacreu J, García-Carreira MC, et al. Wernicke's encephalopathy in non-alcoholic patients: a series of 8 cases. Neurología. 2011;26(9):540-547. doi:10.1016/j.nrl.2011.03.001

35. Nolli M, Barbieri A, Pinna C, Pasetto A, Nicosia F. Wernicke's encephalopathy in a malnourished surgical patient: clinical features and magnetic resonance imaging. Acta Anaesthesiol Scand. 2005;49 (10):1566-1570. doi:10.1111/j.1399-6576.2005.00879.x

36. D'Aprile P, Gentile MA, Carella A. Enhanced MR in the acute phase of Wernicke encephalopathy. Am J Neuroradiol. 1994;15(3):591-593.
37. Maeda M, Tsuchida C, Handa Y, Ishii Y. Fluid attenuated inversion recovery (FLAIR) imaging in acute Wernicke encephalopathy. Radiat Med. 1995;13(6):311-313.

38. Yokote K, Miyagi K, Kuzuhara S, Yamanouchi H, Yamada H. Wernicke encephalopathy: follow-up study by ct and mr. J Comput Assist Tomogr. 1991;15(5):835-838. doi:10.1097/00004728-199109 000-00022

39. Mascalchi M, Simonelli P, Tessa C, et al. Do acute lesions of Wernicke's encephalopathy show contrast enhancement? Report of three cases and review of the literature. Neuroradiology. 1999;41 (4):249-254. doi:10.1007/s002340050741

40. White ML, Zhang Y, Andrew LG, Hadley WL. MR imaging with diffusion-weighted imaging in acute and chronic Wernicke encephalopathy. Am J Neuroradiol. 2005;26(9):2306-2310.

41. Park SH, Kim M, Na DL, Jeon BS. Magnetic resonance reflects the pathological evolution of Wernicke encephalopathy. J Neuroimaging. 2001;11(4):406-411.

42. Doss A, Mahad D, Romanowski CAJ. Wernicke encephalopathy: unusual findings in nonalcoholic patients. J Comput Assist Tomogr. 2003;27(2):235-240. doi:10.1097/00004728-20030300000022

43. Jung Y-C, Chanraud S, Sullivan EV. Neuroimaging of Wernicke's encephalopathy and Korsakoff's syndrome. Neuropsychol Rev. 2012;22(2):170-180. doi:10.1007/s11065-012-9203-4

44. Zahr NM, Pfefferbaum A. Alcohol's effects on the brain: neuroimaging results in humans and animal models. Alcohol Res. 2017;38(2):183-206.

45. Segobin S, Ritz L, Lannuzel C, et al. Integrity of white matter microstructure in alcoholics with and without Korsakoff's syndrome. Hum Brain Mapp. 2015;36(7):2795-2808. doi:10.1002/ hbm. 22808

46. Nahum L, Pignat JM, Bouzerda-Wahlen A, et al. Neural correlate of anterograde amnesia in Wernicke-korsakoff syndrome. Brain Topogr. 2015;28(5):760-770. doi:10.1007/s10548-014-0391-5

47. Paul LK, Erickson RL, Hartman JA, Brown WS. Learning and memory in individuals with agenesis of the corpus callosum. Neuropsychologia. 2016;86:183-192. doi:10.1016/j. neuropsychologia.2016.04.013

48. Heaton RK, Chelune G, Talley J, Kay GG, Curtiss G. Wisconsin Card Sorting Test Manual: Revised and Expanded. Odessa, FL: Psychological Assessment Resources; 1993.

49. Kurki T, Himanen L, Vuorinen E, et al. Diffusion tensor tractography-based analysis of the cingulum: clinical utility and findings in traumatic brain injury with chronic sequels. Neuroradiology. 2014;56(10):833-841. doi:10.1007/s00234-014-1410-7

50. Koikkalainen J, Rhodius-Meester H, Tolonen A, et al. Differential diagnosis of neurodegenerative diseases using structural MRI data. NeuroImage Clin J. 2016;11:435-449. doi:10.1016/j.nicl.2016. 02.019

51. Pasquier F, Leys D, Weerts JGE, Mounier-Vehier F, Barkhof F, Scheltens $\mathrm{P}$. Inter-and intraobserver reproducibility of cerebral atrophy assessment on mri scans with hemispheric infarcts. Eur Neurol. 1996;36(5):268-272. doi:10.1159/000117270

52. Caine D, Halliday GM, Kril JJ, Harper CG. Operational criteria for the classification of chronic alcoholics: identification of Wernicke's encephalopathy. J Neurol Neurosurg Psychiatry. 1997;62(1):51-60. doi:10.1136/jnnp.62.1.51

53. Verfaellie M, Cermak LS, Blackford SP, Weiss S. Strategic and automatic priming of semantic memory in alcoholic Korsakoff patients. Brain Cogn. 1990;13(2):178-192. doi:10.1016/02782626(90)90049-T

54. Rensen YCM, Oosterman JM, Walvoort SJW, Eling PATM, Kessels RPC. Intrusions and provoked and spontaneous confabulations on memory tests in Korsakoff's syndrome. J Clin Exp Neuropsychol. 2017;39(2):101-111. doi:10.1080/13803395.2016.1204991 
55. Bowden S. Separating cognitive impairment in neurologically asymptomatic alcoholism from Wernicke-Korsakoff syndrome: is the neuropsychological distinction justified? Psychol Bull. 1990;107 (3):355-366. doi:10.1037/0033-2909.107.3.355

56. Leng NRC, Parkin AJ. Double dissociation of frontal dysfunction in organic amnesia. Br J Clin Psychol. 1988;27(4):359-362. doi:10.1111/j.2044-8260.1988.tb00800.x

57. Shoqeirat MA, Mayes A, MacDonald C, Meudell P, Pickering A. Performance on tests sensitive to frontal lobe lesions by patients with organic amnesia: leng \& Parkin revisited. Br J Clin Psychol. 1990;29 (4):401-408. doi:10.1111/j.2044-8260.1990.tb00903.x

58. Nyhus E, Barceló F. The wisconsin card sorting test and the cognitive assessment of prefrontal executive functions: A critical update. Brain Cogn. 2009;71(3):437-451. doi:10.1016/j.bandc.2009.03.005

59. Zuccoli G, Cravo I, Bailey A, Venturi A, Nardone R. Basal ganglia involvement in Wernicke encephalopathy: report of 2 cases. $\mathrm{Am}$ J Neuroradiol. 2011;32(7):E129-131. doi:10.3174/ajnr.A2185

60. Sullivan EV, Zahr NM, Sassoon SA, et al. The role of aging, drug dependence, and Hepatitis C comorbidity in alcoholism cortical compromise. JAMA Psychiatry. 2018;75(5):474-483. doi:10.1001/ jamapsychiatry.2018.0021

61. Sawyer KS, Maleki N, Papadimitriou G, Makris N, Oscar-Berman M, Harris GJ. Cerebral white matter sex dimorphism in alcoholism: A diffusion tensor imaging study. Neuropsychopharmacology. 2018;43(9):1876-1883. doi:10.1038/s41386-018-0089-6

62. Victor M, Adams RD, Collins GH. The Wernicke-Korsakoff Syndrome and Related Neurologic Disorders Due to Alcoholism and Malnutrition (Contemporary Neurology). 2nd ed. Philadelphia, PA: F. A. Davies Company; 1989.

63. Eggspühler AW, Bauerfeind P, Dorn T, Siegel AM. Wernicke encephalopathy - A severe neurological complication in a clinically inactive Crohn's disease. Eur Neurol. 2003;50(3):184-185. doi:10.1159/ 000073064

64. Palazon Cabanes B, Martinez Lerma EJ, Fuentes Fernandez I, Hernandez Clares R. Late presentation of wernicke's encephalopathy after gastrectomy in a patient with gastric adenocarcinoma: case report [article in Spanish]. Acta Neurol Colomb. 2015;31(4):412-416.

65. Pantoni L, Poggesi L, Repice A, Inzitari D. Disappearance of motor tics after Wernicke's encephalopathy in a patient with Tourette's syndrome. Neurology. 1997;48(2):381-383. doi:10.1212/WNL.48.2.381

66. Rodríguez-Pardo J, Puertas-Muñoz I, Martínez-Sánchez P, De Terán JD, Pulido-Valdeolivas I, Fuentes B. Putamina involvement in Wernicke encephalopathy induced by Janus Kinase 2 inhibitor. Clin Neuropharmacol. 2015;38(3):117-118. doi:10.1097/WNF.000 0000000000083

67. Kilinc O, Caferov K, Koytak PK, Gunal DI, Uluc K. Wernicke's encephalopathy in two different clinical settings: one after whipple surgery and the other due to alcohol abuse. J Neuropsychiatry Clin Neurosci. 2015;27(1):e71-e72. doi:10.1176/appi.neuropsych.13110354

68. Sostak P, Padovan CS, Yousry TA, Ledderose G, Kolb HJ, Straube A. Prospective evaluation of neurological complications after allogeneic bone marrow transplantation. Neurology. 2003;60(5):842-848. doi:10.1212/01.WNL.0000046522.38465.79
69. Soulaidopoulos S, Ioannidou M, Chalevas P, Cholongitas E. Wernicke encephalopathy: A "complication" of acute liver failure. Nutr Clin Pract. 2015;30(6):847-848. doi:10.1177/0884533615602001

70. Tan JH, Ho KH. Wernicke's encephalopathy in patients with hyperemesis gravidarum. Singapore Med J. 2001;42(3):124-125. doi:10.1136/pgmj.58.683.558

71. MacLean JB. Wernicke's encephalopathy after gastric plication. JAMA . 1982;248(11):1311. doi:10.1001/jama.1982.033301100 19016

72. Jiang W, Gagliardi JP, Raj YP, Silvertooth EJ, Christopher EJ, Krishnan KRR. Acute psychotic disorder after gastric bypass surgery: differential diagnosis and treatment. Am J Psychiatry. 2006;163 (1):15-19. doi:10.1176/appi.ajp.163.1.15

73. Anoop T, Rose L, Sathy M, Kumar A, Radha T, Thomas M. Hyperemesis gravidarum-induced Wernicke's encephalopathy. J R Coll Psysicians Edinb. 2009;39:125-128.

74. Ashraf V, Prijesh J, Praveenkumar R, Saifudheen K. Wernicke's encephalopathy due to hyperemesis gravidarum: clinical and magnetic resonance imaging characteristics. J Postgrad Med. 2016;62 (4):260. doi:10.4103/0022-3859.191005

75. Hunt SA, Kay-Lambkin FJ, Baker AL, Michie PT. Systematic review of neurocognition in people with co-occurring alcohol misuse and depression. $J$ Affect Disord. 2015;179:51-64. doi:10.1016/j. jad.2015.03.024

76. Mann K, Günther A, Stetter F, Ackermann K. Rapid recovery from cognitive deficits in abstinent alcoholics: A controlled test-retest study. Alcohol Alcohol. 1999;34(4):567-574. doi:10.1093/alcalc/ 34.4.567

77. Sechi G, Sechi E, Fois C, Kumar N. Advances in clinical determinants and neurological manifestations of B vitamin deficiency in adults. Nutr Rev. 2016;74(5):281-300. doi:10.1093/nutrit/ nuv 107

78. Ohkoshi N, Ishii A, Shoji S. Wernicke's encephalopathy induced by hyperemesis gravidarum. Associated with bilateral caudate lesions on computed tomography and magnetic resonance imaging. Eur Neurol. 1994;34(3):177-180. doi:10.1159/000117034

79. Brière FN, Rohde $\mathrm{P}$, Seeley JR, Klein D, Lewinsohn PM. Comorbidity between major depression and alcohol use disorder from adolescence to adulthood. Compr Psychiatry. 2014;55 (3):526-533. doi:10.1016/j.comppsych.2013.10.007

80. Isenberg-Grzeda E, Chabon B, Nicolson SE. Prescribing thiamine to inpatients with alcohol use disorders: how well are we doing? $J$ Addict Med. 2014;8(1):1-5. doi:10.1097/01.ADM.0000435 320.72857.c8

81. Pitel AL, Beaunieux H, Witkowski T, et al. Episodic and working memory deficits in alcoholic Korsakoff patients: the continuity theory revisited. Alcohol Clin Exp Res. 2008;32(7):1229-1241. doi:10.1111/ j.1530-0277.2008.00677.x

82. Wijnia JW, Goossensen A. Cerebellar neurocognition and Korsakoff's syndrome: an hypothesis. Med Hypotheses. 2010;75 (2):266-268. doi:10.1016/j.mehy.2010.02.035
Neuropsychiatric Disease and Treatment

\section{Publish your work in this journal}

Neuropsychiatric Disease and Treatment is an international, peerreviewed journal of clinical therapeutics and pharmacology focusing on concise rapid reporting of clinical or pre-clinical studies on a range of neuropsychiatric and neurological disorders. This journal is indexed on PubMed Central, the 'PsycINFO' database and CAS, and is the official journal of The International Neuropsychiatric Association (INA). The manuscript management system is completely online and includes a very quick and fair peer-review system, which is all easy to use. Visit http://www.dovepress.com/testimonials.php to read real quotes from published authors. 